In particular, Webster stresses the importance for Freud of Haeckel's "biogenetic law" - the by now longdiscredited principle that ontogeny recapitulates phylogeny. But, oblivious to Freud's background in biology - it was in fact Haeckel's brand of Darwinism that had stimulated Freud to take up studies in science in the first place - Webster supposes it was Wilhelm Fliess, Freud's biologist friend, who equipped him, late in the day, with such a viewpoint. And this helps to obscure a much larger truth.

Webster is astute in perceiving as fundamental to Freudian interpretation what he dubs Freud's "theory of correspondences" - a mode of ontogenetic reductionism accomplished by appeals to homologies and analogies whereby, in Freud's scheme of things, every silk purse can inevitably be unmasked as nothing but its "prototype" or "imago" - that is, a sow's ear. And he recognizes a basic epistemological kinship between the heuristic styles of Freud and Fliess - for, throughout his writings on biorhythms, Fliess also uses an audacious reductive methodology based on the principle of the prototype (Webster's "lowest common denominator").

But the author supposes that Freud arrived at this mode of interpretation in his clinical practice in the years after 1910 , whereas in fact it had by then long been the quintessence of the Freudian style; and he fails to appreciate the origins of this approach in the unconstrained morphological conjecture characteristic of comparative anatomists and zoologists in Germany from Goethe to Haeckel luminaries whose works were fundamental in shaping the thought systems of Freud, Fliess and several of their late nineteenth-century scientific contemporaries.

Historically speaking, the doctrines of Freud and Fliess are properly seen as bastard children of nineteenth-century morphological science. But this means, in effect, that both men's thought systems are throwbacks to the Naturphilosophie of the Romantics and the "natural supernaturalism" of the German idealist philosophers (re-tailored for the Anglophone world by Thomas Carlyle, the Alpine Christian). And it is no coincidence that basic to their programmes was precisely the sort of secularization of biblical motifs that Webster here attributes to Freud.

A less polemical and more informative "critical intellectual biography", then, would trace the materialistic pantheism of Freudian theory to its more immediate sources (Carlyle among them). And such a book - one that would inevitably comprehend Freud's life as one actually lived on the model of a Bildungsroman - might well vindicate Webster in his identification of Freud as Messiah, showing him to be more on target in some of his intuitions than even he himself knows.
With its trenchant assault on the empirical and logical foundations of Freud's theory-building and its cogent depiction of psychoanalysis as a religion, Webster's book, albeit largely derivative, stands as a valid and important addition to the literature. Its value as a contribution to history is vitiated, however, by the author's lamentable ignorance of the cultural and scientific contexts in which Freud worked and of which he was very much a product, and his wanton disregard of much of the primary material that illuminates his intellectual genealogy.

Emboldened by his demolition work and concerned to write more than just another polemic against Freud, Webster ends by trumpeting an oddly messianic note of his own - that out of the ashes of psychoanalysis a new psychology can now arise on the wings of neo-Darwinism. But his phoenix fails to take flight, for he omits to say what such a psychology might consist of and to what epistemology it might submit. Furthermore, in the wake of the demise of both Marxism and Freudianism, to invest in the basic principle that, with time, through natural selection, a sow's ear can become a silk purse is surely to bet against the odds - this at the very least.

Peter J. Swales, an historian of psychoanalysis, is at 285 Mott Street, New York, New York 10012, USA.

\section{Ancestral patterns}

\section{Jane Maienschein}

Biology Takes Form: Animal Morphology and the German Universities, 18001900. By Lynn K. Nyhart. University of Chicago Press: 1995 Pp. 414. \$75, $£ 59.95$ (hbk); $\$ 27.50$, £21.95 (pbk).

TwENTY years ago, Garland Allen published his Life Science in the Twentieth Century. The first chapter included a seven-page section on "The Science of Morphology", which Allen defined in terms of the study of living forms, tracing common evolutionary ancestors and using the comparative method to reconstruct phylogenies. Ernst Haeckel and August Weismann led the way in a field characterized by speculative theorizing. Then, according to Allen, a younger generation rejected this speculation and phylogenizing, producing a "revolt from morphology". In turn, a younger generation of historians challenged Allen's avowedly Marxist insistence on revolution and suggested a more gradual, evolutionary interpretation of change.

While this discussion was developing, Lynn Nyhart was an undergraduate at Princeton, going on to graduate school at the University of Pennsylvania. She felt that neither Allen's short sketch nor the responses were capturing the great diversity of German morphology. Never an established university discipline, morphological study nonetheless gained a different kind of prominence in German intellectual discussions than either Allen or his critics (who focused on American biology and its German roots) had fully appreciated. Rather than attacking these interpretations, Nyhart instead convincingly shows that we need to go further to explore more of what had been the lively study of morphology - and that it matters for our understanding of science. By offering her compelling study in the spirit of extending scholarship rather than demanding that her own interpretation replace all others, she reveals a healthy open-mindedness. The overall result should be an improved understanding of the scientific enterprise and how to study it. Her book is to be applauded for its good sense and provocative suggestions for valuable new research directions, and should stand as a worthy companion in the German study of form to classic explorations of Darwinian evolution, medical anatomy and embryology.

As Nyhart points out, recognizing the contributions of dozens of researchers as they moved among German universities over a century yields a different perspective than the study of only a single person, place or set of scientific contributions at a particular time. Although she thus lacks detail about the scientific contributions, she sees generational shifts that would otherwise remain invisible. She recognizes that older generations of scientists do not die as quickly as generations of new researchers and approaches appear, and that generations thus overlap intellectually rather than later generations neatly replacing earlier ones. The replacement may be further confounded by lack of institutional opportunities.

In the nineteenth century, E. S. Russell's three stages of morphology prevail (as elaborated in his 1916 book Form and Function): idealism gives way to evolutionary morphology, then to causal experimental analysis. Yet the stages overlap, and the intellectual successes do not map neatly to institutional successes. For example, Haeckel gained prominence for his public espousal of Darwinian evolution or materialistic monism, yet never established an effective research 'school' to produce students to follow and spread his 'truth'.

Nyhart touches on several intriguing questions. How can we explain the intellectual success of the morphological programme when it was never refined as a discipline with university chairs or journals in Germany? Why did Haeckel and his close friend Carl Gegenbaur look like the leaders when they had few students and little direct institutional influence in 
Germany? And what does this case tell us about the nature of science and how we should best study its development?

Nyhart provides some answers. Morphology found niches in other successful disciplines, notably anatomy and scientific zoology. Haeckel stood out partly because of his popular approach and his assertive, indeed bombastic, style, and Gegenbaur developed an exceptionally loyal familylike following among his students, many of whom he placed in foreign universities where they could carry on his research approach and spread his reputation. Finally, we learn that science is done by individuals and embedded in a variety of institutions, in ways that deserve more careful attention, as do the timing of innovations and the generational and power relationships.

We have heard such messages before, but Nyhart is no simple constructionist who thinks that institutions and their context directly cause the science. Rather, the texture of science is rich and varied. We need to explore more aspects, and implicitly all accessible aspects. Along the way, we will even learn much that is instructive for science today, such as the changing relationship of teaching and research, the emphasis on innovation and the competition among epistemological and methodological approaches.

As one of those who challenged Allen's interpretations by calling for a closer study of a wider range of research, I find Nyhart's study exciting, even though she points out that my own emphasis was itself limited in focus and even though she could benefit from a comparison with American and British studies of morphology. She is right: we need a rich diversity of studies in the history of biology, including explorations of odd niches from all sorts of perspectives just as she has persuasively revealed that the science itself is rich and varied.

Jane Maeinschein is in the Departments of Philosophy and Zoology, Arizona State University, Tempe, Arizona 85287-2004, USA.

\section{White heat of medical practice}

\section{W. F. Bynum}

Technology in the Hospital: Transforming Patient Care in the Early Twentieth Century. By Joel D. Howell. Johns Hopkins University Press: 1995. Pp. 341. $\$ 47.50$, £39.95.

ONE modern answer to the old question "Is medicine an art or a science?" might be "Neither, it is a technology". The medicine of the late twentieth century is certainly identified with, and surrounded by, machines, and many of its most dramatic aspects, such as open-heart surgery, nuclear magnetic resonance imaging, hacmodialysis or incubators for premature babies, are more the products of technological realizations than of conceptual transformations. Both the power and the cost of medical care have been irrevocably touched by technology. Several of the innovations supposed to reduce costs, such as keyhole surgery with short hospital stays, also depend on recent and promised future technology.

If technology is simultaneously one of medicine's problems and one of its solutions, it is unlikely to disappear from the medical scene. It is therefore surprising that historians of technology and historians of medicine have generally had so little to say to each other. So Joel Howell's monograph is to be welcomed as a study that takes as its fundamental theme the birth of the modern technologically orientated hospital. Take away hospitals, and most of the really expensive equipment of contemporary medical care would disappear. Why and how did these institutions respond to the lure of the machine? Did it make any difference to their patients?

Howell's study is rooted in the patient records of two particular institutions, the Pennsylvania Hospital in Philadelphia and the New York Hospital in New York City, between 1900 and 1925. His analysis of a statistically significant sample of these records allows him to ask several questions about the nature of hospital medical practice in these decades, which, he convincingly argues, coincide with fundamental transformations. The patient records bear eloquent testimony to change. They more than double in median length, and, more importantly, increase by more than five times in the average daily space a record occupies. This discrepancy highlights the reduced average hospital stay, a result heavily influenced by the coming of routine tonsillectomies. In 1900,2 per cent of patients admitted to the Pennsylvania Hospital were suffering from diseases of the tonsils; in 1925, more than a quarter were. Similar figures obtain for the New York Hospital. Tonsillitis became the most common hospital disease, and the operation by far the most frequent surgical procedure. It first brought children into general hospitals as an ordinary occurrence, almost as a childhood rite of passage.

Howell's quantification of the ton- sillitis phenomenon will probably come as no surprise to many readers with early memories of going under from ether or of ice-cream after surgery. It is almost a byway for Howell, because these children often generated no laboratory tests, such as a urinalysis (almost routine protocol by the end of his period), blood counts (common but still used selectively), bacteriological studies or X-ray examinations. The records of other hospital patients, however, contain the results of these and similar investigations with increasing frequency; often, too, data such as body temperature or pulse rate were collected serially and represented graphically. Blood counts became important for the diagnosis of typhoid fever or the prognosis of pneumonia, and following the discovery of insulin in 1922, the measurement of urinary sugar took on new significance. Printed forms helped to standardize the collection and reporting of data, and the records themselves began to lose the narrative structure that earlier characterized them.

Donating diagnostic blood from a vein, fingertip or ear lobe was a new experience for patients, but nothing captured the public's imagination quite like the $\mathrm{X}$-ray, discovered exactly a century ago and used in medicine within weeks. Howell offers a thoughtful analysis of the assimilation of the $\mathrm{X}$-ray into popular American culture as well as the professional implications of such questions as who pays for, takes and interprets the image. (One early specialist charged less 